\title{
LOTUS PEDUNCULATUS -AN AGRICULTURAL PLANT?
}

\author{
G. W. Sheath
}

Whatawhata Hill Country Research Station, MAF, Hamilton

\section{Abstract}

An extensive underground system that consists of a primary crown and taproot, rhizomes and fibrous roots is a dominant feature of the. growth habit of Lotus pedunculatus The suitability of $L$. pedunculatus as a legume adapted to wet and/or infertile soils may largely depend on the development of this dense, superficial underground system. Autumn expansion of rhizomes, followed by winter fragmentation, results in the spread and propagation of new plant units and highlights the colonizing nature of the plant.

Poor persistence and production are noted features of $L$. pedunculatus in improved, grazed pastures. Slow recovery from defoliation is characteristic of the plant and results from the removal of actively growing shoots and from the delay in reestablishing this shoot population, Lax defoliation encourages more active residual shoot populations, but, because of greater death and decay losses, net herbage productivity may not improve. Identification and development of plants that possess more rapid, early regrowth will be required if $L$. pedunculatus is to become a successful legume in pasture where its relative competitive ability is not favoured by edaphic conditions.

\section{INTRODUCTION}

Lotus pedunculatus is considered to have been introduced into New Zealand agriculture between 1860 and 1870 (Thompson, 1922 ) and its early success as a component of seed mixtures sown into unfertilized, bush areas was reported by Levy (1932). By the late 1940s, Saxby (1948) reported that the distribution of L. pedunculatus was widespread throughout high rainfall areas of New Zealand and at that time he recommended its use in moist, summer hill country where little or no topdressing was possible. Its use in the development of acid, waterlogged peat lands in New Zealand has also been advocated (Levy, 1970) and it is for this purpose that it has been most successfully used overseas (Howell, 1948;

Barnard, 1969; Charlton, 1975). 
More recently in New Zealand, interest in extending the use of L. pedunculatus into more improved,fertile pastures has increased. This principally resulted from the release of 'Grasslands Maku', a tetraploid $L$. pedunculatus (Armstrong, 1974) and from the identification of its inherent insect resistance (Farrell and Sweney, 1972), non-bloating characteristics (Jones et al., 1970) and efficient soil phosphate uptake properties (Brock, 1973). However, the ability of $L$. pedunculatus to persist within grazed, competitive pastures is poor on medium to high fertility soils (Sheath et al., 1977; Brock and Charlton, 1978). This paper reviews those characteristics of $L$. peduculatus that determine its present agricultural suitability, and suggests changes that will be required if it is to be successfully used within improved, fertile pastures.

\section{UNDERGROUND CHARACTERISTICS}

The growth habit of established L. pedunculatus (Fig. 1) is dominated by an underground system that consists of a central crown and taproot that links a superficial network of rhizomes and associated fibrous roots (MacDonald, 1946). Expansion of this system occurs during late summer/autumn and can involve a large accumulation of dry matter, particularly where defoliation

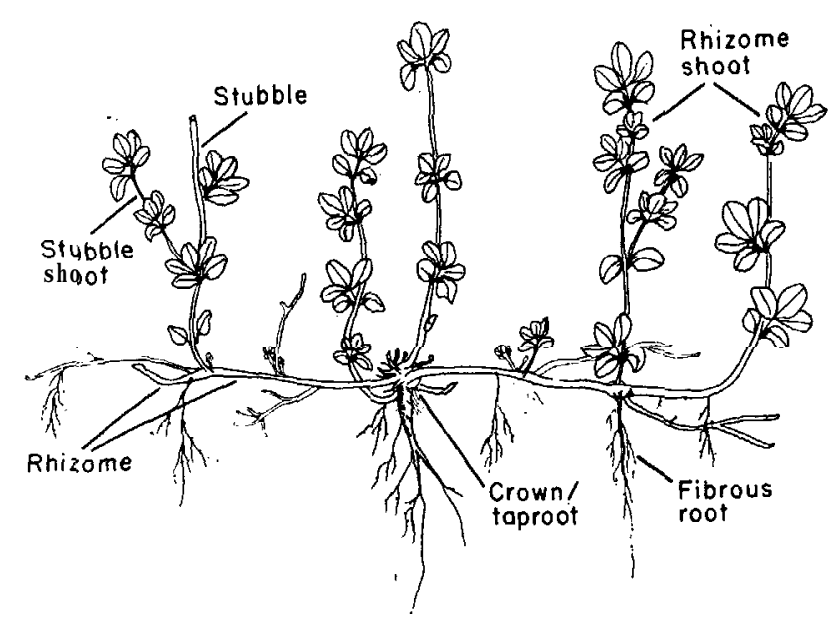

FIG. 1: A generalized diagram of the growth habit of Lotus pedunculatus. 
TABLE 1: UNDERGROUND BIOMASS (t DM/ha) AND TOTAL NON-STRUCTURAL CARBOHYDRATE CONCENTRATIONS* $(\%$ DRY WEIGHT) FOR A 2-YEAR-OLD STAND OF PURE 'GRASSLANDS MAKU'

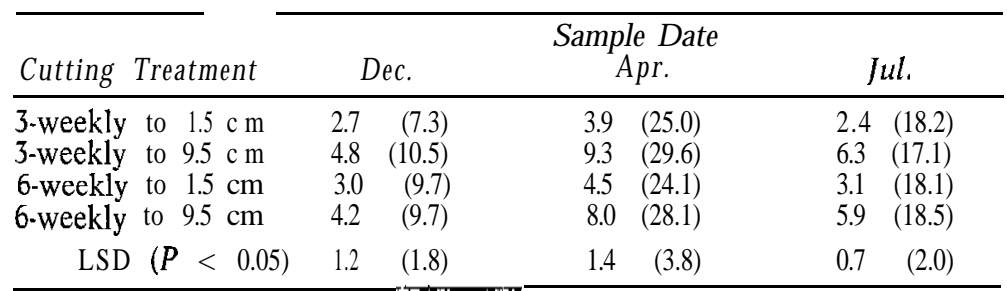

*In parenthesis.

is more lenient (Table 1). During winter and spring, much of this growth is lost as old rhizomes break down and multicrowned plants fragment. The resultant propagation of new, discrete plant units (Table 2) highlights the inherent colonizing ability of $L$. pedunculatus which must, in part, account for the species' success as a pioneer legume. Rhizome growth is encouraged by the restriction of autumn defoliation, but this conflicts with short-term herbage production as growth is partitioned away from aerial production. In the experiment associated with Table 1, net herbage production during autumn ranged from 0.5 to $0.9 \mathrm{t} \mathrm{DM} / \mathrm{ha}$, while underground biomass Increased by as much as 3.0 to $4.0 \mathrm{t}$ $\mathrm{DM} /$ ha under lenient defoliation for the same period.

Associated with seasonal changes in underground biomass are autumn maximum, and late spring minimum concentrations of stored non-structural carbohydrate in the rhizomes, crown and taproot (Table 1). Direct involvement of stored starch in shoot regrowth appears to be minimal (Sheath, 1978), although it would seem to act as a respiratory substrate for underground organs during winter and spring. As such, stored sugars and starch play

TABLE 2: PLANT DENSITIES IN A 2-YEAR-OLD, PURE 'GRASSLANDS MAKU' STAND (PLANTS/ml)

\begin{tabular}{lcc}
\hline & \multicolumn{2}{c}{ Sample D ate } \\
Cutting Treatment & Jan. & Sep. \\
\hline 3-weekly to $1.5 \mathrm{~cm}$ & 179 & 170 \\
3-weekly to $9.5 \mathrm{c} \mathrm{m}$ & 153 & 242 \\
6-weekly to $1.5 \mathrm{~cm}$ & 155 & 182 \\
6-weekly to $9.5 \mathrm{c} \mathrm{m}$ & 159 & 225 \\
LSD $(\mathrm{P}<0.05)$ & 76 & 63 \\
\hline
\end{tabular}


an important part in maintaining a basis for shoot initiation, and hence production, within the plant.

The turf-forming habit of L. pedunculafus results from a dense superficial distribution of rhizomes and associated fibrous roots within the upper 5 to $10 \mathrm{~cm}$ of soil. This shallow rooting system, plus the presence of air spaces in the root cortex (Soper, 1959), allows the species to survive and produce under waterlogged conditions (Barnard, 1969). Futhermore, a high concentration of roots occurs where plant-available phosphate predominantly exists under low fertility conditions, Thus, its ability to compete and produce under low phosphate conditions (Brock, 1973; Nordmeyer and Davis, 1977) results more from the efficient recovery of soil phosphate than from the efficient usage of the assimilated nutrient.

The success of $L$. pedunculatus as a nitrogen fixing legume on acid soils $(\mathrm{pH}<5.0)$ can partly be related to the acid tolerance of its associated rhizobia (Norris, 1965). Correction of soil $\mathrm{pH}$ to 5.5 to 6.0 may be beneficial for establishment and production, but it is not essential (Greenwood, 1961; Lowther, 1977). Tolerance to aluminium toxicity, due to reduced uptake and translocation of aluminium to the shoots, has also been suggested as a means by which L. pedunculafus successfully grows on acid soils with high available aluminium (Nordmeyer and Davis, 1977). Nitrogen fixation rates in established plants are comparable with white clover but growth of associated grasses is generally less (Brock, 1973; Nordmeyer and Davis, 1977). Wide $\mathrm{C} / \mathrm{N}$ ratios and high tannin levels in organic matter derived from L. pedunculafus are suggested causes of slow mineralization rates and reduced nitrogen availability for grass growth.

\section{SHOOT CHARACTERISTICS}

In established plants, initiation of new growth from the crown is confined to late summer/autumn and this generally continues in the form of rhizomes. Thus, the principal underground sites for the initiation of leafy aerial shoots are swollen rhizome nodes. Initiation and development of rhizome shoots are reduced as defoliation becomes more lenient and/or infrequent, especially during late spring and summer (Table 3). As above-ground herbage is allowed to accumulate, there is a greater tendency for initial axillary growth from rhizome nodes to. commence as laterally growing rhizomes, rather than leafy aerial shoots. Thus, to estab- 
TABLE 3: NUMBER OF RHIZOME SHOOTS AND STUBBLE SHOOTS* PARTICIPATING IN REGROWTH OF 'GRASSLANDS MAKU' (PER PLANT)

\begin{tabular}{lrrrrrr}
\hline \multirow{2}{*}{ Cutting Treatment } & \multicolumn{2}{c}{ N ov. } & \multicolumn{2}{c}{ Sample Date } \\
Feb. & \multicolumn{2}{c}{ May } \\
\hline 3-weekly to $1.5 \mathrm{~cm}$ & 20.0 & $(20.2)$ & 20.7 & $(12.4)$ & 22.3 & $(8.3)$ \\
3-weekly to $9.5 \mathrm{~cm}$ & 4.4 & $(14.3)$ & 7.4 & $(6.2)$ & 19.6 & $(3.1)$ \\
6-weekly to $1.5 \mathrm{~cm}$ & 11.4 & $(13.8)$ & 12.6 & $(16.8)$ & 21.2 & $(5.9)$ \\
6-weekly to $9.5 \mathrm{~cm}$ & 4.4 & $(8.8)$ & 7.0 & $(8.8)$ & 16.6 & $(2.8)$ \\
LSD $(P<0.05)$ & 3.7 & $(5.2)$ & 2.9 & $(3.7)$ & 4.0 & $(2.6)$ \\
\hline
\end{tabular}

*In parenthesis.

lish a new rhizome shoot pool following the defoliation of large canopies, a release of leafy axillary buds and/or a transition from rhizome forms to leafy aerial shoots is required. Such a release and transition involves delays in shoot developnient and, as with creeping rooted and rhizomatous lucerne types (Heinricks et al., 1977), these delays can lead to slow early regrowth. Because of the indeterminate nature of above-ground, and the opportunity for continued underground expansion of rhizomes, there appears to be no means by which a cluster of leafy shoots can develop in the base of the canopy.

The consequences of these delays in rhizome shoot initiation and development are likely to be most evident during the cooler and less active spring period and they may account for the October-November production "troughs" recorded by Suckling (1960) and Sithamparanathan (1979). More frequent and/or severe defoliation will increase the number of rhizome shoots participating in regrowth, but such managements still conflict with increasing herbage productivity (Sheath, 1980).

New shoot growth can also develop from above-ground nodes on both intact and defoliated (stubble) stems. Greater initiation and development of stubble shoots generally occur within smaller canopies that result from more severe and/or frequent defoliation (Table 3) . Where the viability and leaf complement of the supporing stubble are poor, stubble shoots are less prevalent. Thus, their involvement in regrowth is less during dry summer/autumn and cold winter conditions. Following defoliation, regrowth rates of stubble shoots initially increase, but they may then decline as rhizome shoots begin to dominate regrowth. Stubble shoots, therefore, form a more transient shoot population. 


\section{CANOPY CHARACTERISTICS}

The dynamics of regrowth in $\mathbf{L}$. pedunculafus depend largely on the nature of the defoliation regimes imposed. For example, initial regrowth in 'Grasslands Maku' following cutting to $1.5 \mathrm{~cm}$ consists of both stubble and rhizome shoots, but the latter quickly and increasingly dominate the canopy as regrowth continues (Fig. $2 \mathrm{~A})$. In contrast, the contribution that stubble shoots make to regrowth is greater with higher, $9.5 \mathrm{~cm}$ cutting and it is maintained for a longer time (Fig. 2B).

As a result of this greater contribution, early total shoot regrowth is often greater, but because of larger dry matter losses from the death and disappearance of a greater stubble component, early net canopy growth rates are much the same for the two regimes. In both situations, realization of potentially high rhizome shoot growth rate occurs with the lengthening of spelling intervals. However, large canopies may develop and, following defoliation, early shoot regrowth from poor residual populations is slow (Fig. $2 \mathrm{C})$. Net regrowth patterns therefore depend on the extent to which rhizome shoot regrowth can dominate; superficial stubble shoot regrowth can develop; and within-canopy dry matter losses occur.

Defoliation of $L$. pedunculatus removes the most dominant and actively growing shoots; thus initial regrowth is highly dependent on the nature of the residual shoot population. Unlike lucerne,

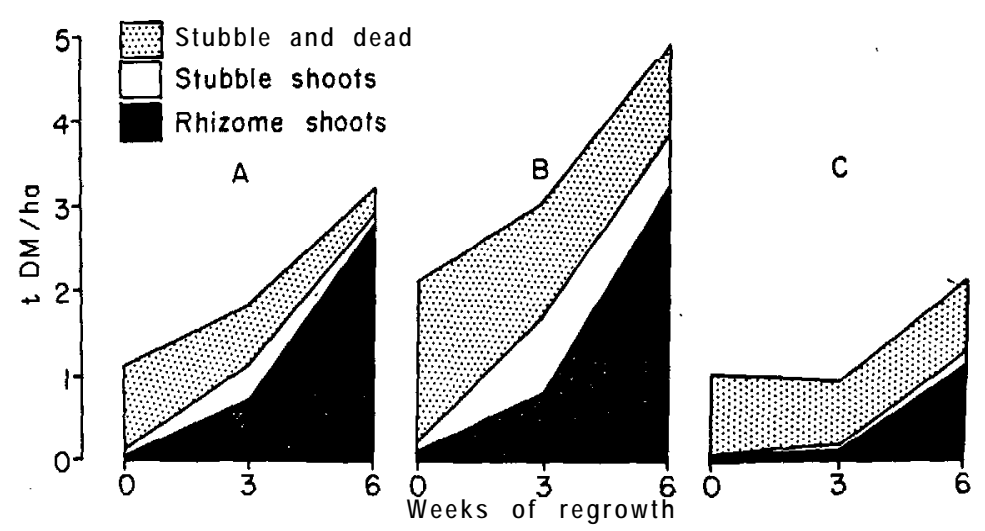

FIG. 2: Dry matter changes in the components of ' $G$ rasslands Maku' for three independent regrowth cycles. (See text for details of cycles $A, B, C$ ). 
extended spelling dces not encourage the development of a residual basal shoot population and the re-establishment of actively growing rhizome shoots is slow. Furthermore, where stubble shoot regrowth is encouraged by lenient defoliation, so also are large dry matter losses from increased stubble and dead matter components. Generally, therefore, early regrowth in L. pedunculatus is typically slow during the first 2 or 3' weeks following defoliation. Management seems to have little positive influence in overcoming delays in the initiation of new shoots, a process that seems to be governed by the demands of the plant's present, indeterminate growth habit. The better performance of more prostrate $\mathbf{L}$. pedunculatus cultivars in hard-grazed, mixed swards (Harris et al., 1973; Lambert et al., 1974) would seem to relate to their greater ability to retain a more active residual shoot population that can commence immediate regrowth following defoliation.

\section{AGRICULTURAL SUITABILITY}

With its present adaptations and morphological form, L. pedunculatus would appear to be well suited as an agricultural plant in acid, low fertility, wet soils where other legumes have difficulty in establishing and/or persisting. The longer-term success of L.pedunculatus in waterlogged, peat or second-class wet hill lands is well recognized (Levy, 1970) and its more recent extension into South Island high country has received considerable attention (Lowther, 1977; Nordmeyer and Davis, 1977). With improved seed size and seedling vigor, and with an increased production potential (Armstrong, 1974), the more recently available 'Grasslands Maku' cultivar should promote the success of the species as a perennial pasture legume in these situations. Futhermore, where competition from companion species is minimal, L. pedunculatus is likely to be more tolerant of hard grazings (Howell, 1948; Charlton, 1975) for its typically slow early regrowth will be less critical in determining its persistence and production.

Where edaphic limitations are only minor constraints to the growth of other pasture plants, the poor performance of L. pedunculatus within mixed competitive pastures must largely relate to its inability to rapidly recover from grazing. Unlike ryegrass or white clover, whose actively growing meristems are not readily removed during grazing, L. pedunculatus has difficulties in retaining and/or re-establishing a rapidly growing shoot population. As a result, the development of a competitive leaf complement is slow. In lucerne and L. corniculatus, plants that have a similar 
requirement to quickly re-establish an active shoot population, the need for specialized grazing management has long been recognized. If present commercial forms of $L$. pedunculatus are to succeed in mixed pastures where they are not favoured by edaphic conditions, similar recognition of specialized management requirements must also be given.

In compromising between better early regrowth and total shoot production, lax rotational grazing appears to be the most appropriate management for maintaining the persistence and production of L. pedunculatus in these pastures. This may be best achieved with cattle rather than sheep, but in either situation it will also result in low pasture utilizatjon and high dry matter losses from senescence and decay processes. Only during warm, moist summer conditions when regrowth rates of L. pedunculatus are greatest, is it likely that it can tolerate hard grazing within a mixed, competitive pasture.

In considering the development of a more suitable L. pedunculatus plant for grazed pastures of moderate to high fertility, selection for rapid early regrowth, paticularly with reference to the productive rhizome shoot pool, would appear to be essential. Plants capable of concentrating the release of basal shoots, with which grazing could coincide, would most likely provide the best 'basis for improved regrowth. As with lucerne (Leach, 1977), genotypes that are more determinate in growth habit should possess this characteristic. Such types will be less likely to promote extensive rhizome growth, but as rhizome-associated advantages are less important in these situations, reduced underground demand for assimilates should further aid in improving the plants' agricultural performance. Unless improved regrowth characteristics are identified and developed, it would seem unlikely that $\mathbf{L}$. pedunculatus will become an important legume component of grazed, mixed pastures where its competitive ability is not favoured by edaphic conditions.

\section{REFERENCES}

Armstrong, C. S., 1974. N.Z. /l exp. A gric., 2: 333-6.

Barnard, C., 1969. Herbage Plant Species. Div. P1. Ind., CSIRO. pp. 81-3. Brock, J. L., 1973. N.Z. Jl agric. R es., 16: 483-91.

Brock, J. L.; Charlton, J. F. L., 1978. Proc. N.Z. G rassld A ss., 39: 121-9. Charlton, J. F. L., 1975. J. Br. Grassld Soc., 30: 251-9.

Farrell, J. A. K.; Sweney, W. J., 1.972. N.Z. Jl agric. R es., 15: 904- 58.

Greenwood, R. M., 1961. Ibid., 4: 375-89.

Harris, A. J., et al., 1973. N.Z. Jl exp. A gric., I: 139-63. 
Heinricks, D. J.; Goplen, B. P.; Hanna, M. R., 1977. Can. J. PI Jici, 57: 221-5.

Howell, H. B., 1948. Oregon A gric. Exp. Sta. Bull. 456. 25 pp.

Jones, W. T.; Lyttelton, J. W.; Clarke, R. T. J., 1970. N.Z. Jl agric. Res., 13: $149-56$.

Lambert, J. P.; Boyd, A. F.; Brock, J. L., 1974. N.Z. JI exp. Agric., 2: 359-63.

Leach, G. J., 1977. In Plant Relations in Pastures (Ed. J. R. Wilson). CSIRO.

Levy, E. B., 1932. N.Z. Jl A gric., 44: 79-92.

lington.

Lowther, W. L., 1977. Proc. N.Z. Grassld A ss., 38: 133-9,

MacDonald, H. A., 1946. Cornell A gric. Exp. Sta. M em. 261. 156 pp.

Nordmeyer, A. H.; Davis, M. R., 1977. Proc. N .Z. Grassld A SS., 38: 119-25.

Norris, D. O., 1965. Plant and Soil, 22: 143-66.

Saxby, S. H., 1948. N.Z. Jl Agric., 77': 360-2.

Sheath, G. W., 1978. Ph.D thesis, Massey University.

— 1980. N.Z. Jl agric. Res., 23: 191-200.

Sheath, C. W.; Galletley, W. S.; Greenwood, P., 1977. Proc. N.Z. Grassld A SS., 38: 140-50.

Sithamparanathan, J., 1979. N.Z. $l l$ exp. A gric., 7: 163-7.

Soper, K., 1959. N.Z. $J l$ agric. Res., 2: 329-41.

Suckling, F. E. T., 1960. Ibid., 3: 579-91.

Thomson, G. M., 1922. The N aturalization of A nimals and Plants in $\mathrm{N}$ ew Zealand. Camb. Univ. Press. 